\title{
Infecção disseminada por Rhodococcus em doente imunossuprimida.
}

\author{
Disseminated Rhodococcus infection \\ in an immunocompromised patient
}

\author{
Sofia Nunes ${ }^{1}$, Daniel Coutinho ${ }^{1}$, Inês Cunha², Rui Moreira ${ }^{3}$ \\ ${ }^{1}$ Serviço de Infecciologia, ${ }^{2}$ Reumatologia e ${ }^{3}$ Cirurgia Geral. Centro Hospitalar do Baixo Vouga EPE, Aveiro. Portugal
}

\begin{abstract}
Resumo
Reconhecido como agente de doença veterinária, o Rhodococcus tem vindo a ser implicado num número crescente de infecções em doentes imunossuprimidos.

Doente do sexo feminino, de 55 anos, com antecedentes de dermatomiosite diagnosticada um ano antes do episódio de doença actual, sob corticoterapia sistémica. Apresentava episódio recente de clínica respiratória com imagiologia sugestiva de embolização séptica, que evoluíra favoravelmente após antibioterapia. Passados 3 meses recorreu ao hospital com sinais inflamatórios da parede abdominal, sendo objectivado extenso abcesso intra-abdominal. Efectuou drenagem cirúrgica e iniciou antibioterapia empírica. Na cultura do pus cresceram bacilos gram positivo, descartados como contaminantes. A repetição da colheita de pus permitiu isolar Rhodococcus spp, tendo sido iniciado esquema combinado com ciprofloxacina e cotrimoxazol. Em ambulatório, após estudo adicional, foi diagnosticado adenocarcinoma gástrico, sendo a doente gastrectomizada e submetida a radioterapia e quimioterapia adjuvante, mantendo antibioterapia supressiva.
\end{abstract}

As infecções em doentes imunossuprimidos requerem um elevado índice de suspeição para agentes atípicos, sendo fundamental o contacto próximo entre o clínico e o microbiologista.

Palabras chave. Dermatomiositis. Paciente inmunocomprometido. Zoonosis. Infección oportunista

\section{Introdução}

Reconhecido como agente de doença veterinária, a doença humana por Rhodococcus equi é pouco frequente. Desde 0 primeiro caso descrito em $1967^{1}$, foi publicada cerca de uma dezena de casos até ao início dos anos 80 . Nos últimos 30 anos tem-se assistido a um claro aumento do número de casos em doentes com disfunção imunitária, sobretudo na infecção pelo vírus da imunodeficiência humana (VIH), mas também em doentes sob terapêuticas imunossupressoras e doentes oncológicos ${ }^{2-7}$.

0 Rhodococcus equié uma bactéria pleomórfica gram positivo, que cresce nos meios de cultura habituais mas é frequentemente interpretada como contaminante. Por conter ácidos micólicos na sua parede celular, pode ser identificada como ácido-álcool resistente e assim confundida com outros agentes, nomeadamente micobactérias e bactérias do género Nocardia ${ }^{8}$. Existe actualmente um painel de testes bioquímicos (API Rapid CORYNE $®$, bioMérieux Vitek Inc., Hazelwood, M0) para a identificação desta bactéria, sendo no entanto essencial a suspeição clínica para a sua utilização $0^{9}$. A resposta imunitária

\begin{abstract}
Known as an animal disease agent, Rhodococcus has been increasingly associated with infection in immunosuppressed patients.

A 55 year-old female patient, diagnosed with dermatomyositis one year before and under corticosteroids, presented with respiratory symptoms and evidence of bilateral pulmonary nodules that responded well to a short course of antibiotics. Three weeks later she presented with inflammatory signs on the abdominal wall and a large intrabdominal abscess was diagnosed. The abscess was surgically drained and antibiotics were started. The pus culture grew gram positive bacilli, disregarded as contamination. Pus culture was repeated, revealing Rhodococcus spp, and antimicrobial therapy was altered to ciprofloxacin and cotrimoxazole. After hospital discharge the patient was diagnosed with gastric adenocarcinoma and underwent surgery, chemotherapy and radiotherapy, maintaining the antibiotic suppressive regimen.
\end{abstract}

A close relationship between the treating physician and the microbiologist is beneficial in diagnosing infections by atypical pathogens in immunosuppressed patients.

Key words. Dermatomyositis. Immunocompromised Patient. Zoonoses. Opportunistic infections

celular parece ser fundamental para o combate a esta infecção, o que explica que $85 \%$ dos casos de doença ocorra em doentes imunocomprometidos 8 .10.

\section{Caso Clínico}

Doente do sexo feminino de 55 anos, com antecedentes de dermatomiosite diagnosticada há cerca de um ano e medicada com prednisolona $40 \mathrm{mg}$ por dia no início do episódio de doença actual. Recorre inicialmente a outro hospital por quadro de pneumonia com derrame parapneumónico, tendo realizado tomografia computadorizada que mostrou nódulos pulmonares à direita. Realizou biópsia transtorácica com histologia sugestiva de embolização séptica, mas sem isolamento microbiológico. Foi medicada com levofloxacina, havendo boa evolução clínica e analítica.

Passados 3 meses inicia dor e sinais inflamatórios da parede abdominal associados a sintomas constitucionais e recorre ao Serviço de Urgência. Ao exame objectivo, de relevo, encontrava-se febril, com diminuição dos sons respiratórios e crepitações em ambas as bases pulmonares sinais inflamatórios com flutuação dos quadrantes direjtos abdominais e edema assimétrico do membro inferior esquerdo. 
Figura 1. Tomografia computadorizada do tórax, abdómen e pelve na admissão hospitalar. Abcesso subcutâneo com extensão intra-abdominal em corte transversal (A) e coronal (B) e envolvimento pulmonar (C).
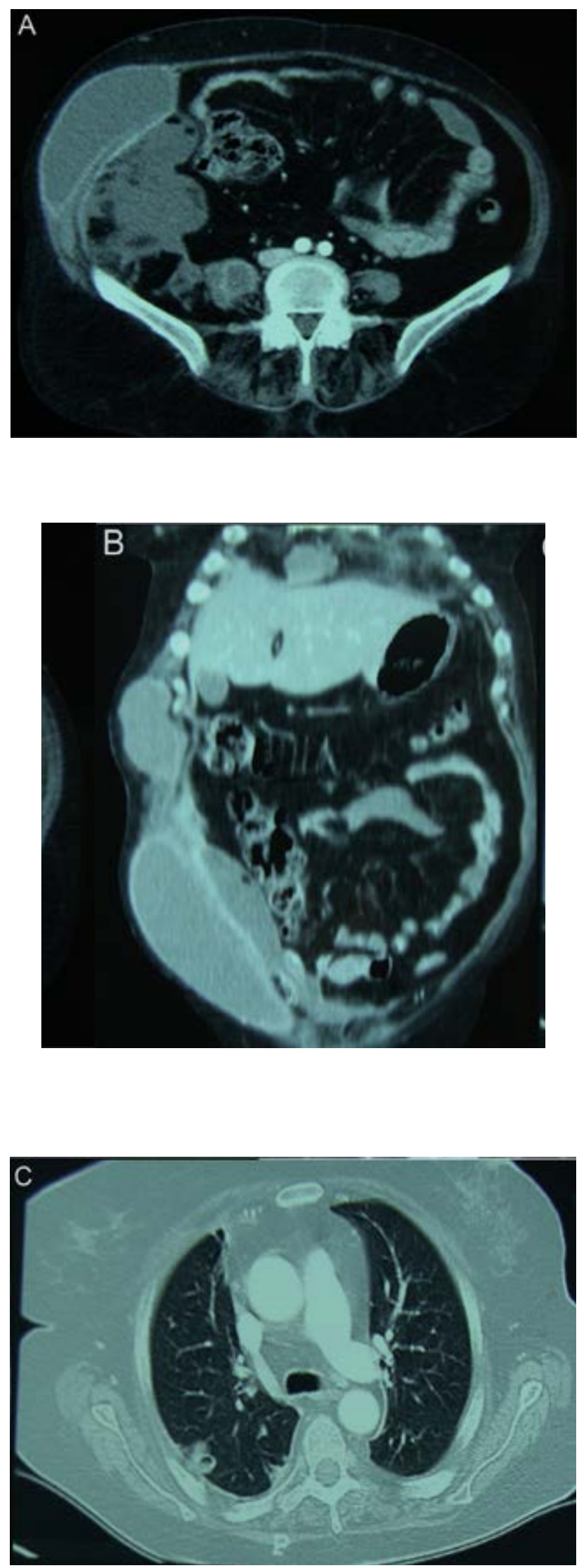

Analiticamente apresentava elevação da proteína C reactiva $(13,11$ $\mathrm{mg} / \mathrm{dL}$ ), leucocitose neutrofílica (26000/mm³ leucócitos, 20150/mm³ neutrófilos), anemia normocrómica normocítica (hemoglobina $11 \mathrm{~g} /$ $\mathrm{dL}$ ), fosfatase alcalina e desidrogenase láctica elevadas (224 U/L e $260 \mathrm{U} / \mathrm{L}$, respectivamente) e creatinina quinase normal (8 U/L). Realizou exames que mostraram abcessos subcutâneos, pulmonares e intra-abdominais (Fig. 1), bem como trombose parcial das artérias pulmonares e da veia ilíaca esquerda.

Foi submetida a drenagem parcial do abcesso da parede abdominal e iniciada antibioterapia empírica com tigeciclina e hipocoagulação. As hemoculturas de veia periférica colhidas no Serviço de Urgência foram negativas e no pus da colecção abdominal foram isolados pequenos bacilos gram positivo, descartados como contaminantes. Mantendo ausência de resposta após ser escalada antibioterapia para imipenem, foi alertado o Laboratório de Microbiologia para a suspeita de agentes atípicos e alterada antibioterapia para cotrimoxazol. Foi repetida a drenagem cirúrgica de pus, cuja cultura foi positiva para Rhodococcus spp, tendo sido associada a ciprofloxacina ao cotrimoxazol, verificando-se evolução clínica, analítica e imagiológica favorável (Fig. 2).

Em ambulatório, no decurso de anemia sintomática, efectuou estudo complementar que revelou adenocarcinoma do antro gástrico (pT3N2Mx), sendo a doente submetida a gastrectomia subtotal com radioterapia e quimioterapia adjuvantes. Manteve antibioterapia supressiva com ciprofloxacina e cotrimoxazol, sem evidência de reactivação da infecção, e dose baixa de manutenção de prednisolona. Após período aparentemente livre de doença oncológica, houve recidiva com metastização ganglionar, óssea e pulmonar, vindo a doente a falecer 16 meses após a cirurgia oncológica inicial.

\section{Discussão}

0 Rhodococcus equi existe de forma ubiquitária no solo e a principal via de transmissão parece ser a inalação de aerossóis ou ingestão de partículas contaminadas com o agente. A maioria dos casos de doença por Rhodococcus cursa com clínica de infecção pulmonar, podendo coexistir manifestações extrapulmonares em até $20 \%$ dos $\operatorname{cas}^{8,9}$. Esta bactéria tem um perfil variável de sensibilidade aos antimicrobianos, sendo geralmente sensível aos macrólidos, rifampicina, aminoglicosídeos, vancomicina, imipenem, quinolonas, tetraciclinas, clindamicina, cotrimoxazol e linezolide. 0 tratamento exige antibioterapia prolongada em regime de combinação de dois ou três fármacos, durante duas a oito semanas ${ }^{9}$. Doentes com infecção grave e imunossupressão mantida poderão beneficiar de manter antibioterapia supressiva crónica $^{10}$. 0 prognóstico da infecção por Rhodococcus é pior nos doentes infectados pelo VIH, estando descrita uma taxa de mortalidade de $58 \%$ neste grupo, $20 \%$ nos imunocomprometidos por outras causas e $11 \%$ nos imunocompetentes ${ }^{8}$.

Os autores apresentam este caso para realçar a necessidade de um elevado índice de suspeição para o diagnóstico de infecções por agentes pouco comuns em doentes imunodeprimidos. Nestes casos torna-se especialmente importante 0 contacto próximo entre o clínico assistente e o microbiologista para o diagnóstico correcto e atempado.

Este caso sugere a importância do rastreio das doenças neo- 
Figura 2. Evolução radiológica às 12 semanas de antibioterapia dirigida em tomografia computadorizada do abdómen e pelve [cortes transversal (A) e coronal (B)] e pulmonar (C).
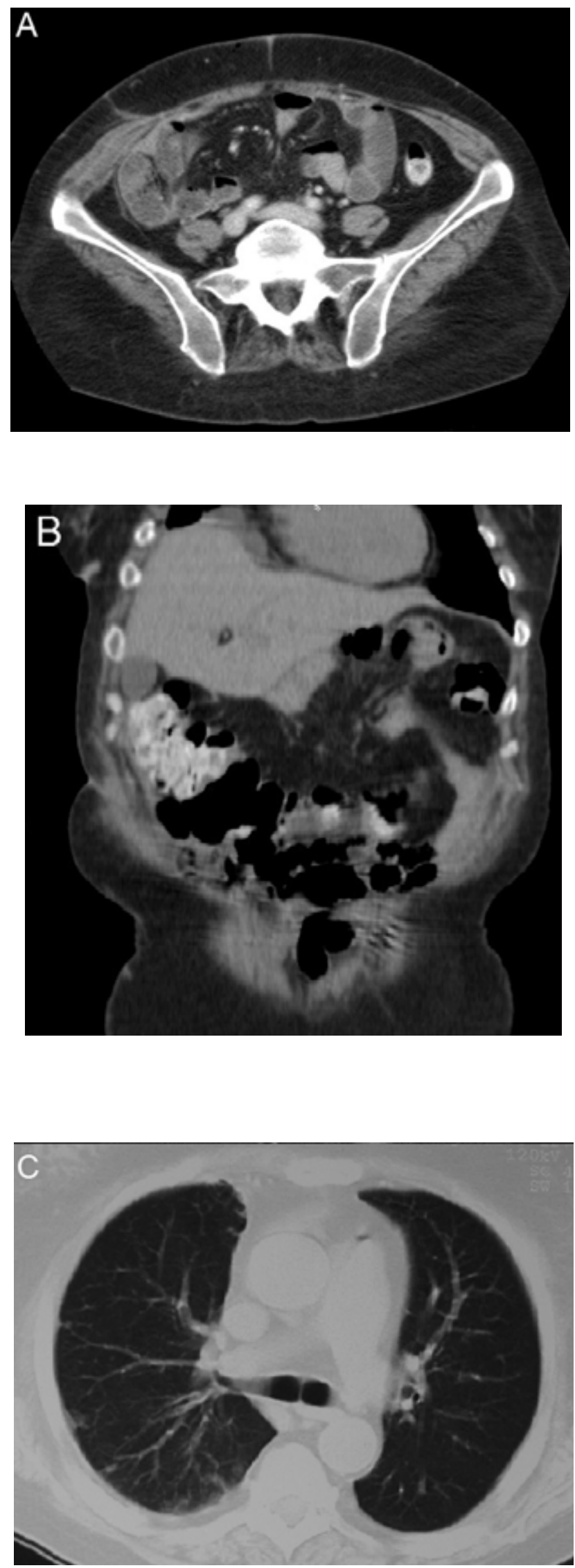

plásicas em doentes com dermatomiosite, não só aquando do diagnóstico, mas de forma periódica nos primeiros anos após 0 início do seguimento. Um estudo aprofundado e multidisciplinar é essencial para o esclarecimento etiológico de quadros clínicos complexos.

\section{Bibliografia}

1. Golub B, Falk G, Spink W. Lung abscess due to Corynebacterium equi. Report of first human infection. Ann Intern Med 1967; 66:1174.

2. Messias A, Araújo C, Lino S, Pacheco T, Mansinho K, Ordway D, Ventura F. Condensação pulmonar cavitada por Rhodococcus equi num indivíduo seropositivo para 0 VIH. Acta Med Port 2000; 13:329-53.

3. Henriques J, André M, Santiago F, Pardal C, Abecassis M, Pina J. Pneumonia a Rhodococcus equi em doentes com SIDA. Acta Med Port 2000; 13:49-53.

4. Esteves P, Mineiro A, Serrado M, Diniz A. Pneumonia por Rhodococcus equi em doente VIH (+): A propósito de uma associação rara. Rev Port Pneumol 2007; XIII (5): 703-9

5. Faria J, Simões J, Eiras E, Furtado A. Infecção pulmonar por Rhodococcus equi em doente $\mathrm{VIH}+$. A propósito de um caso. Galicia Clin 2013; 74 (1):29-32.

6. Sá D, Velez J, Coelho S, Freitas F, Ramalheira E, Oliveira F, Oliveira C. Artrite Séptica por Rhodococcus spp em Transplantado Renal. A Propósito de um Caso Clínico. Rev Port Doenças Infec 2011; 7(1): 40-3.

7. Carmo C, Joosten A, Fernandes M, Campante F. Endocardite e espondilodiscite por Rhodococcus equi num doente imunocompetente. Rev Port Doenças Infec 2012; 8(3): 149-54.

8. Meyer D, Reboli A. Other Coryneform Bacteria and Rhodococci (Chapter 206). In Mandell, Douglas and Bennett's Principles and Practice of Infectious Diseases. 7th Edition. Churchill Livingstone 2010.

9. Slater LN. Microbiology, pathogenesis and epidemiology of Rhodococcus equi infections. Clinical features, diagnosis, therapy and prevention of Rhodococcus equi infections. UpToDate® 2013.

10. Yamshchikov AV, Schuetz A, Marshall Lyon G. Rhodococcus equi infection. Lancet Infect Dis 2010:10:350-9. 